\title{
Physiological Behaviour and Yield Contribution of Oryza sativa Under Different Cultivation System in Boro Season
}

\author{
Md. Shoriful Islam ${ }^{1 *}$, Md. Moinul Hoque ${ }^{1}, K^{2}$ amal Uddin Ahamed ${ }^{1}$, \\ Parvin Akter Bithy ${ }^{1}$ and Sarmin Akter Ranu ${ }^{1}$ \\ ${ }^{1}$ Department of Agricultural Botany, Sher-e-Bangla Agricultural University, Dhaka-1207, Bangladesh.
}

Authors' contributions

This work was carried out in collaboration among all authors. Author MSI designed the study, performed the statistical analysis, wrote the protocol and wrote the first draft of the manuscript. Authors MMH, KUA, SAR and PAB managed the analyses of the study. Authors MSI, SAR and PAB managed the literature searches. All authors read and approved the final manuscript.

Article Information

DOI: $10.9734 / A R R B / 2021 /$ v36i330349 Editor(s):

(1) Dr. Md. Torequl Islam, Federal University of Piaui, Brazil.

(1) Md Harunur Rashid, University of Newcastewers: (2) Zarifth Shafika Kamarudin, University Kebangsaan Malaysia, Malaysia. Complete Peer review History: http://www.sdiarticle4.com/review-history/66356

Original Research Article

Received 12 January 2021

Accepted 15 March 2021

Published 05 April 2021

\begin{abstract}
Aims: The objectives of the research work were to evaluate the physiological behaviour and yield contributing attributes of rice under different system of cultivation in boro season.

Study Design: The experiment was laid out in a randomized complete block design (RCBD) with three replications.

Place and Duration of Study: Central research field of Sher-e-Bangla Agricultural University, Dhaka-1207 during November 2015 to May 2016.

Methodology: In this research we used three System of cultivation $\left[\mathrm{T}_{1}\right.$ : Low land transplant (anaerobic) condition; $\mathrm{T}_{2}$ : Raised upland (aerobic) condition, and $\mathrm{T}_{3}$ : Raised transplant (aerobic) condition] and five rice Varieties [ $\mathrm{V}_{1}$ : BRRI hybrid dhan3; $\mathrm{V}_{2}$ :Bolaka; $\mathrm{V}_{3}$ : Moina; $\mathrm{V}_{4}$ : Gold and $V_{5}: B R R I$ dhan 45], where different morpho-physiological data was taken for evaluation their performance. The significance of the difference among the treatment means were estimated by the Duncan's Multiple Range Test (DMRT) at $5 \%$ level of probability [1].

Results: Among the different system of cultivation significant variation was observed on growth,
\end{abstract}


yield and yield contributing parameters. All the studied hybrid varieties showed superiority in respect of physiological characters, yield and yield attributes in anaerobic condition over aerobic condition. BRRI hybrid dhan3 provided the highest grain yield $\left(8.05 \mathrm{t} \mathrm{ha}^{-1}\right)$ at low land transplant condition. BRRI hybrid dhan3 performed well due to yield attributes [amount of chlorophyll $(2.47 \mathrm{mg}$ $\mathrm{g}^{-1}$ ) in its flag leaves,leaf area index (4.25), shoot reserve translocation (34.97\%), grain dry matter accumulated from current photosynthesis (85.87\%), higher filled grains per panicle and 1000 grain weight] than others varieties and the lowest $\left(4.28 \mathrm{t} \mathrm{ha}^{-1}\right)$ was obtained from BRRIdhan45 at raised transplant condition.

Conclusions: The results showed that Low land transplant condition with BRRI hybrid 3 showed the best performance regarding growth, yield and yield contributing characters of Boro rice varieties than others.

Keywords: Rice; system of cultivation; hybrid; yield.

\section{INTRODUCTION}

Rice is the second most widely grown cereal and primary source of food for more than half of the world population, and about $90 \%$ of the world rice is grown in Asia which is carrying about $60 \%$ of the world population [2]. Rice is not only the foremost staple food but it also provides nearly $48 \%$ of the rural employment, about two-third of the total calories supply and about one-half of the protein intake of an average person in the country [3]. The population of Bangladesh is increasing at an alarming rate and the cultivable land is decreasing due to urbanization and industrialization resulting in the shortage of food. The nation is still adding about 2.3 million every year to its total of 150 million people [4]. Population growth required a continuous increase in rice production in Bangladesh. So, the highest priority has been given to produce more rice. Rice yields are either stagnating/declining in post-green revolution era mainly due to system of cultivation,late or early planting, imbalance use of fertilizer, irrigation and weeding schedule, type of cropping system practiced, lack of suitable rice genotypes for low moisture adaptability and disease resistance [5].

About $90 \%$ of the world's rice production is harvested from irrigated or rainfed lowland rice fields.

One third of the World's developed freshwater is used to irrigate rice [6] with this figure being half of all freshwater supplies for Asia But scarcity of water is getting a problem everywhere in the irrigated ecosystem. Rice requires soil moisture content of $70 \%$ throughout the season [7]. Continuous flooding is no more needed to have a good yield of rice. Aerobic system of rice cultivation has been developed very recently where rice can be grown successfully with saving of $40-70 \%$ irrigation water $[8,9,7]$ i.e. it requires less water than lowland rice. In aerobic system, water is made available (through rainfed or irrigation practice) to a level when the plant really deserves it to maintain its sound physiological system. Currently, aerobic system of rice cultivation has been advocated towards saving irrigation water for Boro rice (Satter, 2009).

The conventional (submerged) irrigated system requires $3500-5000 \mathrm{~L}$ of water for $1 \mathrm{~kg}$ of rice grain production [6,7]. The dwindling of fresh water resources in coming years forced the farmers to grow rice in aerobic condition under water limiting situation. As fresh water for irrigation is getting increasing scarce, system of aerobic rice cultivation is being expanded as an appropriate technology into regions with more intensive cropping in the year to come. Rice growing countries like India, China and Vietnam has already given their attention on system of aerobic rice cultivation including hybrid rice in it. The System of Rice Intensification (SRI) has been promoted for more than a decade as a set of agronomic management practices for rice cultivation that enhances yield [10].

In general, hybrids are known to have more tolerance to abiotic stresses because of their genetic plasticity [11]. As far as it is known, no hybrid rice variety has been released in Bangladesh considering the case of aerobic condition. So, suitability of hybrid rice varieties is to be found out for aerobic situation. Since hybrid rice is a new introduction to our country and for the same reason, not much research works have been done on it. Research on aerobic cultivation of hybrid rice is absent or meager in Bangladesh. So, it is imperative/ needed to generate information on agronomic and physiological performance of hybrid rice varieties in aerobic condition for extending/ intensify its cultivation at 
irrigation limited area in Boroseason. Considering the above-mentioned facts and based on the prior observation, an investigation was undertaken to evaluate the physiological behaviour and yield contributing attributes of rice varieties under different system of cultivation.

\section{MATERIALS AND METHODS}

\subsection{Experimental Site}

The experiment was conducted at the experimental field of Sher-e-Bangla Agricultural University, Dhaka-1207 from November 2015 to May 2016.The soil of the experimental field belongs to the general soil type, shallow red brown terrace soil with silty clay in surface and silty clay loam in sub-surface region. Soil $\mathrm{pH}$ was 6.7 and has organic carbon $0.45 \%$.

\subsection{Varieties and Treatment of the Experiment}

The experiment was comprised of two factors- a) System of cultivation(3): $\mathrm{T}_{1}$ : Low land transplant (anaerobic) condition; $\mathrm{T}_{2}$ : Raised upland (aerobic) condition, and $\mathrm{T}_{3}$ : Raised transplant (aerobic) condition, and factors- b)Variety(5): $\mathrm{V}_{1}$ :BRRI hybrid dhan3; $\mathrm{V}_{2}$ : Bolaka; $\mathrm{V}_{3}$ : Moina; $\mathrm{V}_{4}$ : Gold and $\mathrm{V}_{5}$ : BRRI dhan 45 .

\subsection{Layout and Land Preparation of the Experiment}

The experiment was laid out in a randomized complete block design (RCBD) with three replications. There were 45 plots of size $2.5 \mathrm{~m} \times$ $4 \mathrm{~m}$ in each of 3 replications. The treatments of the experiment were assigned at random into each replication following the experimental design.

\subsection{Seedlings Emergence}

The seedlings were raised in seedbed and 21 days old seedlings were transplanted in the experimental plot. Various system of cultivation maintaining the standard spacing of $25 \mathrm{~cm} \mathrm{x}$ $15 \mathrm{~cm}$ with two seedlings hill-1.The fertilizers were applied as per recommendation and other intercultural operations were done whenever necessary.

\subsection{Data Collection}

Data were recorded as the average of same 10 hills selected at random from the outer side rows (started after 2 rows from outside) of each plot from which different data were collected. Data on the following parameters were recorded during the course of the experiment such as -Plant height, Leaves per hill, Leaf area index, Chlorophyll content, Tillers per hill. Dry matter per hill, Shoot dry matter accumulation and its remobilization to grain, Grain dry matter from current photosynthate,Grains per panicle, 1000 grain weight, Grain yield, Biological yield and Harvest index (\%).

\subsection{Statistical Analysis}

The data obtained for different characters were statistically analyzed by using MSTAT-C softwere to observe the significant difference among the treatment. The mean values of all the characters were calculated and analysis of variance was performed. The significance of the difference among the treatment means were estimated by the Duncan's Multiple Range Test (DMRT) at 5\% level of probability [1].

\section{RESULTS AND DISCUSSION}

The findings have been presented and discussed by using tables, graphs and possible interpretations given under following headings:

\subsection{Plant Height}

Cultivation system affected the plant height of rice significantly at 75DAT and at harvest (Table 1). The tallest plant $(69.28$ and $102.70 \mathrm{~cm}$ at 75DAT and at harvest, respectively) was recorded with $T_{1}$ (Low land transplant condition) treatment. In contrast, the shortest plant (63.22 $\mathrm{cm}$ ) was recorded from $\mathrm{T}_{3}$ (Raised transplant condition), which was statistically similar with $T_{2}$ treatment (Raised upland condition) at 75DAT and at harvest. The height of rice plant is directly related to the depth of water and generally increases with increasing water depth [12]. Khaliq and Cheema, [13] also observed tallest plant in the water logged condition and shortest plant height in alternate wet and dry condition. With advancing plant age, water requirement increased and reducing water to field capacity condition significantly reduced plant height especially at maturity as well as tiller production during later growth stages. Beyrouty et al. [14] also observed reduction in plant height but not tiller production when flood was delayed. 


\subsection{Leaves Per Hill}

Significant variation was observed in case of leaves per hill as influenced by cultivation system of Boro rice at different growth stages (Table 1). Results showed that at all growth stage the highest leaves per hill was recorded by $\mathrm{T}_{1}$ (71.27 and 75.05 at 75 DAT and at harvest, respectively). The results obtained from $T_{3}$ showed the lowest leaves per hill (48.67 and 45.07 at 75 DAT and at harvest, respectively) which was statistically similar with $\mathrm{T}_{2}$ at 75 DAT and at harvest.

\subsection{Leaf Area Index}

Significantly varied result was observed in case of leaf area index as influenced by cultivation system of Boro rice at different growth stages (Fig. 1). Result showed that the highest leaf area index was recorded by $\mathrm{T}_{1}(4.13)$, which was statistically similar with $\mathrm{T}_{2}$. The results obtained from $\mathrm{T}_{3}$ showed the lowest leaf area index (3.73). Saikia $U$ et al [15] also reported that Water stress also caused drastic reduction in LAI, which ranged from 11.1 to $22.5 \%$ (vegetative stage) and 12.2 to $18.8 \%$ (reproductive stage) over the controls.

\subsection{Chlorophy II Content}

In the present investigation there was a significant decrease in the total chlorophyll content in the plants of raised upland condition while under normal rained condition (Fig. 2). Results showed that the highest chlorophyll content was recorded by $T_{1}\left(2.36 \mathrm{mg} \mathrm{g}^{-1}\right)$. The results obtained from $\mathrm{T}_{3}$ showed the lowest chlorophyll content $\left(2.26 \mathrm{mg} \mathrm{g}^{-1}\right)$. Jahan, et al.
[16] and Chutia, et al. [17] also reported that the total chlorophyll content in the plants reduced under water stress condition.

\subsection{Tillers Per Hill}

Significantly varied result was observed in case of tillers per hill as influenced by cultivation systems Boro rice at different growth stages (Table 2). Results showed that at all growth stage the highest tillers per hill was recorded by $\mathrm{T}_{1}$ (18.67 and 32.20 at 75 DAT and at harvest respectively). The results obtained from $T_{3}$ showed the lowest tillers per hill (11.07 and 11.5375 DAT and at harvest, respectively) which was statistically similar with $\mathrm{T}_{2}$ at 75 DAT. Rice growth low land transplant condition give higher tillers per hill than raised upland condition, comparable with raised transplant condition. This finding is in agreement with Anwar et al. 2010 [18]. Toung and Bouman [19] also found the highest tillers per hill in the saturated condition.

\subsection{Dry Matter Per Hill}

Significantly varied results were observed in terms of dry weight per hill as influenced by different cultivation system Boro rice at different growth stages (Table 2). Results showed that at all growth stage the highest dry weight per hill was recorded by $\mathrm{T}_{1}(27.99,46.27$ and $68.87 \mathrm{~g}$ at vegetative, flowering and harvest, respectively). The results obtained from $\mathrm{T}_{3}$ showed the lowest dry weight per hill (15.50, 33.87 and $45.73 \mathrm{~g}$ at vegetative, flowering and harvest, respectively). The results obtained from all other treatments showed significantly different results compared to the highest and the lowest result of dry weight per hill.

Table 1. Effect of cultivation systems of rice on the plant height and leaves per hill

\begin{tabular}{|c|c|c|c|c|c|c|c|c|}
\hline \multirow[t]{2}{*}{ Treatment } & \multicolumn{4}{|c|}{ Plant height (cm) } & \multicolumn{4}{|c|}{ Leaves per hill } \\
\hline & 75 DAT & & at har & & 75 DAT & & at har & \\
\hline $\mathrm{T}_{1}$ & 69.28 & a & 102.7 & $a$ & 71.27 & $a$ & 75.05 & $a$ \\
\hline $\mathrm{T}_{2}$ & 64.38 & b & 98.97 & b & 55.13 & b & 46.8 & $b$ \\
\hline $\mathrm{T}_{3}$ & 63.22 & b & 98.77 & $b$ & 48.67 & $b$ & 45.07 & $b$ \\
\hline $\operatorname{LSD}_{(0.05)}$ & 4.738 & & 2.813 & & 10.16 & & 6.029 & \\
\hline CV $(\%)$ & 7.29 & & 6.59 & & 7.63 & & 10.35 & \\
\hline
\end{tabular}




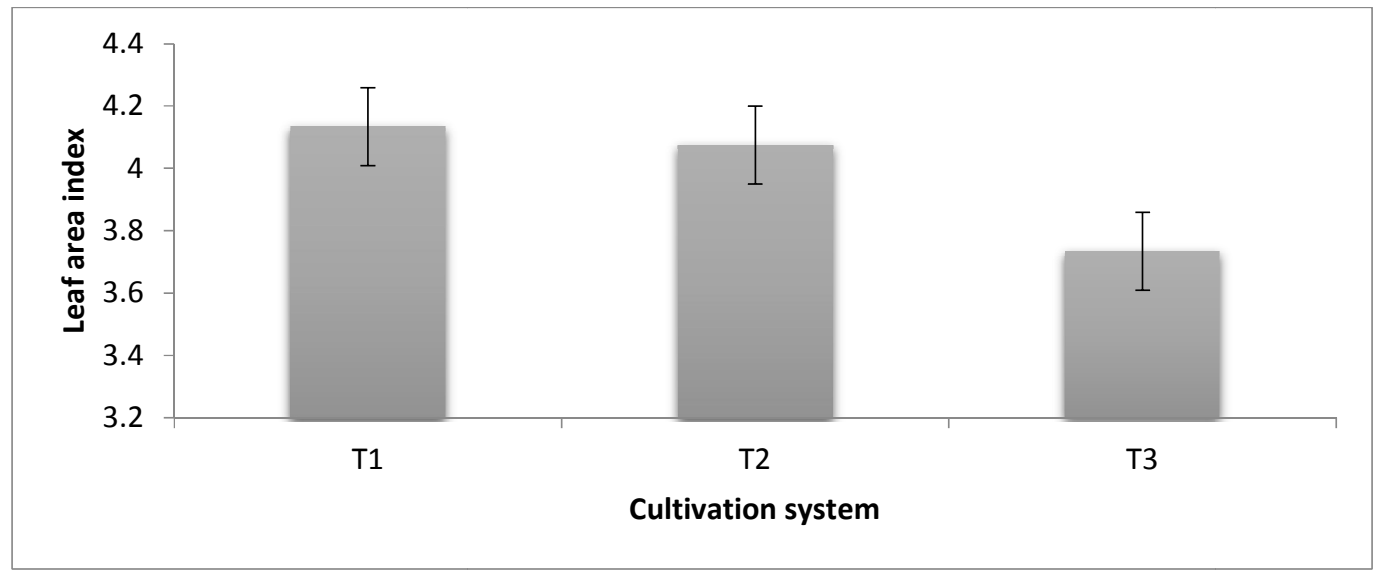

Fig. 1. Effect of cultivation systems on leaf area index of rice

$T_{1}=$ Low land transplant condition, $T_{2}=$ Raised upland condition, $T_{3}=$ Raised transplant condition; Vertical bar represents $L S D$ value

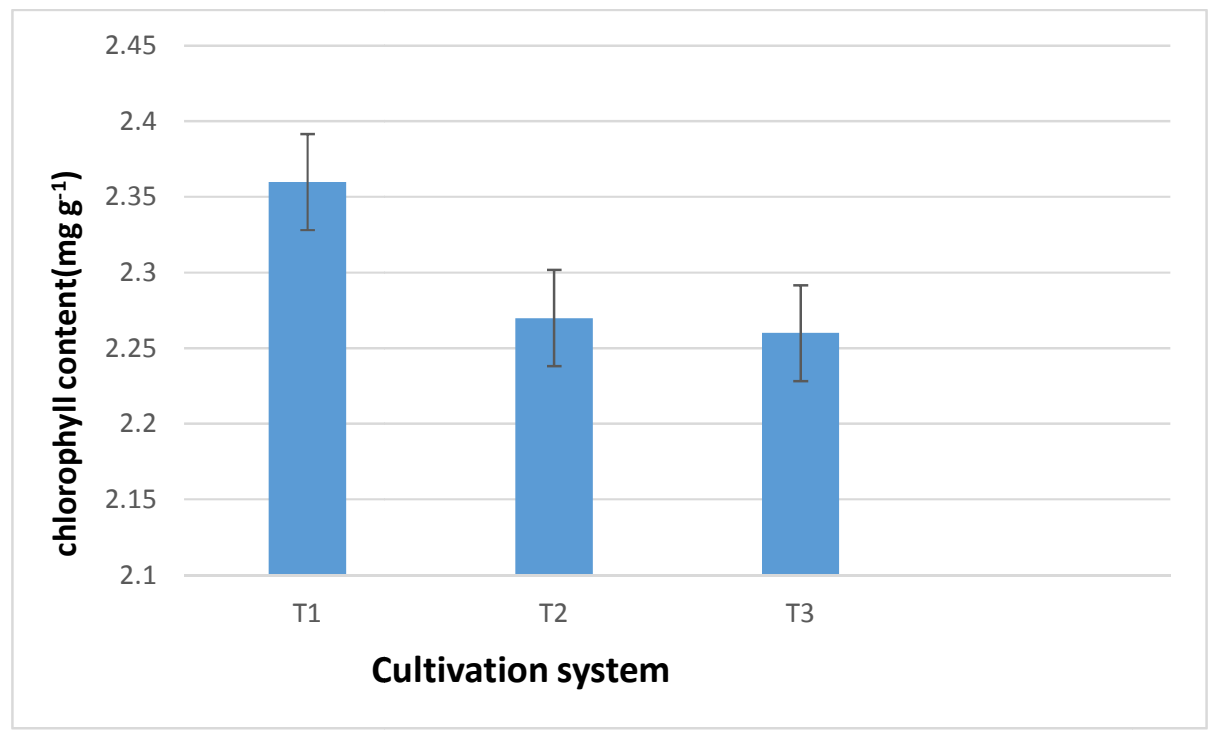

Fig. 2. Effect of cultivation system on chlorophyll content of rice varieties

$T_{1}=$ Low land transplant condition, $T_{2}=$ Raised upland condition, $T_{3}=$ Raised transplant condition; Vertical bar represents $L S D$ value

Table 2. Effect of cultivation systems on the tillers per hill and dry matter per hill of rice varieties

\begin{tabular}{|c|c|c|c|c|c|c|c|c|c|c|}
\hline \multirow[t]{2}{*}{ Treatment } & \multicolumn{4}{|c|}{ Tillers per hill } & \multicolumn{6}{|c|}{ Dry matter per hill } \\
\hline & \multicolumn{2}{|c|}{75 DAT } & \multicolumn{2}{|c|}{ At harvest } & \multicolumn{2}{|c|}{ Vegetative stage (g) } & \multicolumn{2}{|c|}{ Flowering stage (g) } & \multicolumn{2}{|c|}{ At harvest (g) } \\
\hline$\overline{T_{1}}$ & 18.67 & $\mathrm{a}$ & 32.20 & $\mathrm{a}$ & 27.99 & a & 46.27 & $\mathrm{a}$ & 68.87 & a \\
\hline $\mathrm{T}_{2}$ & 12.47 & $b$ & 16.60 & $b$ & 17.79 & $a b$ & 49.00 & a & 60.40 & $b$ \\
\hline $\mathrm{T}_{3}$ & 11.07 & $b$ & 11.53 & c & 15.50 & $b$ & 33.87 & $b$ & 45.73 & c \\
\hline $\operatorname{LSD}_{(0.05)}$ & 1.50 & & 4.32 & & 11.79 & & 8.58 & & 7.57 & \\
\hline $\mathrm{CV}(\%)$ & 9.33 & & 8.72 & & 6.43 & & 9.93 & & 10.33 & \\
\hline
\end{tabular}


Table 3. Effect of cultivation systems on shoot dry matter accumulation, its translocation to the grain and grain dry matter accumulation from current photosynthesis in rice

\begin{tabular}{|c|c|c|c|c|c|c|c|c|c|c|}
\hline \multirow{2}{*}{$\begin{array}{l}\text { Treatment } \\
T_{1}\end{array}$} & \multicolumn{2}{|c|}{$\begin{array}{l}\text { Shoot dry mater at } \\
\text { flowering stage }(\mathrm{g})\end{array}$} & \multicolumn{2}{|c|}{$\begin{array}{l}\text { Shoot dry mater at } \\
\text { maturity stage }(\mathrm{g})\end{array}$} & \multicolumn{2}{|c|}{$\begin{array}{l}\text { Changes in shoot dry } \\
\text { mater }(\mathrm{g})\end{array}$} & \multicolumn{2}{|c|}{$\begin{array}{l}\text { Shoot reserve } \\
\text { translocation (\%) }\end{array}$} & \multicolumn{2}{|c|}{$\begin{array}{l}\text { Grain dry matter from current } \\
\text { photosynthesis (\%) }\end{array}$} \\
\hline & 39.93 & a & 29.79 & $\mathrm{~b}$ & 10.13 & $a b$ & 25.39 & $a$ & 82.19 & $\mathrm{~A}$ \\
\hline $\mathrm{T}_{2}$ & 27.47 & $b$ & 24.23 & $\mathrm{C}$ & 3.23 & $b$ & 11.77 & $b$ & 79.32 & $a b$ \\
\hline $\mathrm{T}_{3}$ & 42.33 & $a$ & 33.47 & $a$ & 8.87 & $a$ & 20.97 & $a$ & 78.08 & $\mathrm{~B}$ \\
\hline $\operatorname{LSD}_{(0.05)}$ & 11.76 & & 3.88 & & 8.28 & & 6.11 & & 3.63 & \\
\hline $\mathrm{CV}(\%)$ & 5.89 & & 5.56 & & 7.89 & & 28.56 & & 7.33 & \\
\hline
\end{tabular}

Values with common letter (s) within a column do not differ significantly at $5 \%$ level of probability; $T_{1}=$ Low land transplant condition, $T_{2}=$ Raised upland condition, $T_{3}=$ Raised transplant condition

Table 4. Effect of cultivation systems on yield contributing characters of rice

\begin{tabular}{|c|c|c|c|c|c|}
\hline Treatment & \multicolumn{2}{|c|}{ Filled grain per panicle } & \multicolumn{2}{|c|}{ Unfilled grain per panicle } & Thousand grain weight (g) \\
\hline$T_{1}$ & 159.80 & $\mathrm{a}$ & 17.67 & C & 29.29 \\
\hline $\mathrm{T}_{2}$ & 154.90 & b & 25.60 & $b$ & 28.88 \\
\hline $\mathrm{T}_{3}$ & 152.90 & c & 38.07 & a & 27.62 \\
\hline LSD $(0.05)$ & 3.73 & & 6.47 & & ns \\
\hline CV $(\%)$ & 8.87 & & 7.04 & & 4.97 \\
\hline
\end{tabular}
condition, $T_{3}=$ Raised transplant condition 
Table 5. Effect of cultivation systems on yield and harvest indexof hybrid and inbred rice varieties

\begin{tabular}{|c|c|c|c|c|c|c|}
\hline Treatment & Grain & & Biolog & $\left(h^{-1}\right)$ & Harve & \\
\hline $\mathrm{T}_{1}$ & 7.01 & $a$ & 15.14 & $a$ & 42.02 & A \\
\hline $\mathrm{T}_{2}$ & 5.77 & b & 12.37 & $b$ & 42.34 & $A$ \\
\hline $\mathrm{T}_{3}$ & 5.45 & $b$ & 12.25 & $b$ & 40.59 & $\mathrm{E}$ \\
\hline LSD (0.05) & 0.51 & & 1.14 & & 0.79 & \\
\hline CV (\%) & 5.83 & & 7.08 & & 8.30 & \\
\hline
\end{tabular}

\subsection{Shoot Dry Matter Accumulation and Its Remobilization to Grain}

Significantly varied results were observed in terms of shoot dry matter accumulation as influenced by different cultivation system in Boro rice at flowering and maturity stages (Table 3). Results showed that the highest shoot dry matter accumulation was recorded by $\mathrm{T}_{3}$ (42.43 at flowering). At maturity stage, the highest shoot dry matter accumulation was recorded by $\mathrm{T}_{3}$ $(33.47 \mathrm{~g})$. The reserve translocation was the highest $(25.39 \%)$ from $\mathrm{T}_{1}$ treatment. The results obtained from $\mathrm{T}_{2}$ showed the lowest shoot dry matter accumulation (27.47 and $24.23 \mathrm{~g}$ at flowering and maturity stage, respectively). The reserve translocation was the lowest $(11.77 \%)$ in $\mathrm{T}_{2}$ treatment.

\subsection{Grain Dry Matter from Current Photosynthesis}

Grain dry matter accumulation from current photosynthesis significantly varied on system of Cultivation (Table 3). Results showed that the highest grain dry matter from current photosynthesis recorded by $\mathrm{T}_{1}(82.19 \%)$ where the lowest $(78.08 \%)$ was obtained from $\mathrm{T}_{3}$.

\subsection{Filled Grains Per Panicle}

Different system of cultivation had significant effect on filled grains per panicle (Table 4). Results showed that the highest filled grains per panicle was recorded by $T_{1}$ (159.8) where the lowest compared to the highest and the lowest grains per panicle.

The result under the present study (152.9) was obtained from $T_{3}$. The results obtained from $T_{2}$ showed medium result was similar with the findings of Bouman et al. [8].

\subsection{Unfilled Grains Per Panicle}

Significant influence was observed on unfilled grains panicle ${ }^{-1}$ (Table 4 ) based on different water treatment. Results showed that the highest unfilled grains per panicle was recorded by $\mathrm{T}_{3}$ (38.07) where the lowest (17.67) was obtained from $T_{1}$. The results obtained from $T_{2}$ showed medium result compared to the highest and the lowest grains per panicle.

\subsection{Grain Weight}

Level of water in the field had minor effect on 1000 grain weight rice (Table 4). Results showed that the highest 1000 grain weight was recorded by $T_{1}(29.29 \mathrm{~g})$ where the lowest $(27.62 \mathrm{~g})$ was obtained from $T_{3}$. The results obtained from $T_{2}$ showed medium result compared to the highest and the lowest 1000 grain weight.

\subsection{Grain Yield}

Grain yield of rice was varied remarkably due to different systems of cultivation (Table 5). The highest grain yield was recorded by $\mathrm{T}_{1}\left(7.01 \mathrm{t} \mathrm{ha}^{-}\right.$ $\left.{ }^{1}\right)$ where the lowest $\left(5.45\right.$ tha $\left.^{-1}\right)$ was obtained from $\mathrm{T}_{3}$ treatment, which was statistically similar with $\mathrm{T}_{2}$ treatment. Bouman and Tuong (2010) suggested that there is a reduction in the grain yield in alternate wetting and drying when compared with rice grown with standing water. Grain yield, however decreased significantly when water was reduced to field capacity condition and this was in agreement with previous findings $[14,20]$.

\subsection{Biological Yield}

Biological yield of rice varied significantly due to different system of cultivation (Table 5). Results showed that the highest Biological yield was recorded by $T_{1}\left(15.14 \mathrm{t} \mathrm{ha}^{-1}\right)$ where the lowest (12.25 $\mathrm{t} \mathrm{ha}^{-1}$ ) was obtained from $\mathrm{T}_{3}$, which was statistically similar with $\mathrm{T}_{2}$ treatment.

\subsection{Harvest Index}

Cultivation system had significant effect on harvest index (Table 5). The highest harvest index was recorded by $\mathrm{T}_{2}(42.34)$, which were 
statistically similar with $T_{2}$ treatment. The lowest harvest index (40.59) was obtained from $T_{3}$ treatment.

\section{CONCLUSION}

From the above summary of the study, it can be concluded that in aerobic condition rice demonstrated lower performance due to low leaf area index, chlorophyll content, tillering, shoot dry matter accumulation and grain dry matter from current photosynthesis. Again, among the different cultivation system, low land transplant condition showed the best performance where the raised transplant condition gave the lowest efficiency considering growth, yield and yield contributing characters. As combined effect of the present study low land transplant condition with BRRI hybrid 3 showed the best performance regarding growth, yield and yield contributing characters of Boro rice varieties. However, further study may be needed regarding the other rice varieties with different management practices in different Agro-Ecological Zones (AEZ) of Bangladesh for testing the regional compliance and other quality attributes.

\section{ACKNOWLEDGEMNTS}

The authors of this manuscript would like to thank the Department of Agricultural Botany, Sher-e-Bangla Agricultural University,Dhaka, Bangladesh.The financial assistance of NST fellowship program from Ministry of Science and Technology, Government of the People's Republic of Bangladesh to carry out this research work is thankfully acknowledged.

\section{COMPETING INTERESTS}

Authors have declared that no competing interests exist.

\section{REFERENCES}

1. Gomez KA, Gomez AA. Statistical procedure for agricultural research $\left(2^{\text {nd }}\right.$ edn.). Intl. Rice Res. Inst., A Willey Intl. Sci. 1984;28-192.

2. Haque MM, Pramanik HR, Biswas JK, Iftekharuddaula KM, Mirza Hasanuzzaman. Comparative performance of hybrid and elite inbred rice varieties with respect to their source-sink relationship. The Scientific World J. 2015;1-11.

3. Julfiquar WA, Haque MM, Haque EKGMA, Rashid AM. Current status of hybrid rice research and future program in Bangladesh. Proc. Workshop on use and development of hybrid rice in Bangladesh, held at BARC. 2009;18-19.

4. Momin SI, Husain M, Technology development and dissemination to augment rice production in Bangladesh. In: The Guardian. 2009;33-35.

5. Prakash NB. Different sources of silicon for rice farming in Karnataka. Paper presented in Indo-US workshop on silicon in agriculture, held at University of Agricultural Sciences, Bangalore, India; 2010.

6. Bouman BAM. How much water does rice use. Rice Today. 2009;8:28-29.

7. Reddy MD. Report, the sustainable water resource management project in India (India-USA Joint Project), Oryza Exclusive, Oryza.com; 2013.

8. Bouman BAM, Yang Xiaoguang, Wang Huaqi, Wang Zhimin, Zhao Junfang, Chen Bin. Performance of aerobic rice varieties under irrigated conditions in North China. Field Crops Res. 2005;103(3):170-177.

9. Peng S, Bouman BAM, Visperas RM, Castan $^{\sim}$ eda A, Nie L, Park HK. Comparison between aerobic and flooded rice: Agronomic performance in a long-term(8-season) experiment. Field Crops Res. 2006;96:252-259.

10. Kabir H, Uphoff N. Results of disseminating the system of rice intensification with farmer field school methods in Northern Myanmar. Experimental Agriculture.2007;43:463476.

11. BRRI. Annual report for 2012. BRRI Pub. No. 113. Joydebpur, Gazipur. 2013;206252.

12. Datta CD. Grain quality consideration in hybrid rice. In: hybrid rice technology: new development and future prospects. S. S. Virmani, (ed.) IRRI, Manilla, Philippines. 1981;123-130.

13. Khaliq and Cheema. Techniques of seed production and cultivation of hybrid rice. Beijing China. Agricultural Press. 2005;2325.

14. Beyrouty CA, Grigg BC, Nornan RJ, Wells BR. Nutrient uptake by rice in response to water management. J. Plant Nutr. 1994;17:39-55.

15. Saikia U, Rangappa, Krishnappa, Goswami B, Rajkhowa DJ, Ngachan S. Evaluating resilience of upland rice to water stress through study of physiological 
responses in subtropical hills of North East India. Indian Journal of Hill Farming. 2018;31(2):236-242.

16. Jahan Md, Nordin Mohd Nozulaidi, Che Lah, Mohd Yusop, Mohd. Effects of water stress on rice production: Bioavailability of potassium in soil. Journal of Stress Physiology \& Biochemistry. 2013;9:97-107.

17. Chutia, Jnandabhiram, Borah Sailen. Water stress effects on leaf growth and chlorophyll content but not the grain yield in traditional rice ( Oryza sativa Linn.) Genotypes of Assam, India II. Protein and Proline Status in Seedlings under PEG Induced Water Stress. American Journal of Plant Sciences. 2012;03:971-980.
DOI: 10.4236/ajps.2012.37115

18. Anwar MP, Begum M. Tolerance of hybrid rice variety Sonarbangla -1 to tiller seperation. Bangladesh J. Crop Sci. 2010;13-15:39-44.

19. Tuong TP, Bouman BAM. Rice production in water scarce environments. Proceedings of the water productivity workshop. Colombo, Sri Lanka. International water management institute, Colombo, Sri Lanka. 2001;12-14.

20. Grigg BC, Beyroty CA, Nornan RJ, Gbur EF, Hamson MG, Wells BR. Rice responses to changes in flood water and $\mathrm{N}$ turing in Southern USA. Fieldcrop res. 2000;66:73-79.

(c) 2021 Islam et al.; This is an Open Access article distributed under the terms of the Creative Commons Attribution License (http://creativecommons.org/licenses/by/4.0), which permits unrestricted use, distribution, and reproduction in any medium, provided the original work is properly cited.

Peer-review history:

The peer review history for this paper can be accessed here: http://www.sdiarticle4.com/review-history/66356 